\title{
INCOME SUPPORT FOR PERSONS WITH DISABILITIES
}

\author{
Ronald Kneebone and Oksana Grynishak \\ The School of Public Policy, University of Calgary
}

\section{SUMMARY}

Alberta, British Columbia and Ontario all maintain separate income-support programs for the disabled. This paper examines the criteria applicants must meet for each program and traces variations in monthly payment levels in relation to political exigencies and inflationary pressures affecting the cost of living. As it is impossible to settle on a definitive way to measure poverty, the authors present several proposals and compare all of them with the income recipients realize from each of the three programs. While acknowledging that the precise level of income support for the disabled is ultimately a value judgment, they suggest that the existing income-support program provided by the federal government for impoverished seniors is a suitable baseline. The authors crunch the numbers to reveal the amounts Alberta, BC and Ontario would have to spend to bring their existing income-support programs for the disabled up to the level of similar programs for seniors. Finally, they recommend that governments index income support for the disabled to inflation. Governments already take inflation into account for taxpayers and seniors and the authors believe the disabled should not be treated differently.

\footnotetext{
* We thank Jennefer Laidley of the Income Security Advocacy Centre for help with ODSP data. We also thank Kate White and three anonymous referees for very helpful comments. We of course remain responsible for any errors and omissions.
} 


\section{INTRODUCTION}

Communities invariably establish ways by which the better off provide assistance to the less well off. These avenues of support establish what we have come to term the "social safety net." In countries where the public sector is small, the private sector establishes a safety net that includes family and friends, charities, religious-based support programs and food banks. As countries grow wealthier, government-funded programs are generally established to supplement, and sometimes replace, private-sector contributions to the social safety net. In Canada, publicly funded elements of the social safety net are comprised of two broad types. One type is designed to help Canadians when they are economically challenged as a result of having trouble finding employment or because they have retired with insufficient savings. These include Employment Insurance (EI), the Quebec and Canada Pension Plans (Q/CPP), Old Age Security (OAS), the Guaranteed Income Supplement (GIS) and provincial social assistance programs. The second type is meant to aid those with specific needs. These consist of programs to provide health care, address homelessness and rescue those harmed by domestic violence, among others.

This paper examines the operation of the social safety net as it pertains to a particular group of Canadians with specific needs: persons with disabilities. This is a broad topic that justifies the examination of a large number of issues, from levels of income-support to the adequacy of health-care support to the role of public education. Our contribution is rather more limited in scope. It is to highlight that one provincial government in Canada has long had in place an income-support program specifically designed for people with severe disabilities. This program, Assured Income for the Severely Handicapped (AISH), is provided by the Alberta government. Two other provinces, Ontario and British Columbia, have taken smaller steps toward establishing income-support programs that recognize the unique needs of persons with disabilities. We briefly describe all three programs but our focus is on evaluating the adequacy of the income support they provide. We discuss why determining an adequate level of income support is challenging and laden with value judgements. This prompts us to measure the adequacy of income support in a number of different ways, each reflecting a different value judgement.

We show that the AISH program is clearly the most generous in terms of income support, but that it has a chequered history. Recent changes have resulted in that program providing a level of support that is consistent with the level the federal government provides to another group of Canadians in broadly similar circumstances: poor seniors. The programs in Ontario and BC provide significantly less income support, suggesting those governments maintain a different value judgement regarding appropriate levels of support. We avoid imposing our own views on what the appropriate level of income support ought to be. We do, however, offer two suggestions for reform that we believe the majority of Canadians would support. One is to index income support for disabled persons to the rate of inflation. Doing so would be consistent with how governments in Canada treat taxpayers and seniors on public pensions. We see no reason to treat Canadians with disabilities any differently. Our second suggestion is to match support for disabled persons to the level of income support provided to poor seniors. While this will leave those who hold value judgements consistent with higher levels of support dissatisfied, we believe the majority of Canadians will deem it appropriate. 


\section{THE NEED}

Access to disability-related insurance is often based on employment history. Persons with severe disabilities are frequently unable to qualify for private insurance of the sort offered as a workplace benefit because of a tenuous or non-existent employment history. For example, a recent report indicates that only 15 percent of adults with autism spectrum disorders are likely to be able to maintain full-time employment. ${ }^{l}$ The lack of employment history is also a constraint for access to many sources of public insurance. Another recent report shows, for example, that only 30 percent of Albertans with severe and permanent mental illness are eligible to receive income support in the form of CPP disability benefits. ${ }^{2}$ The tax system offers a number of opportunities for persons with disabilities to reduce taxable earned income but applicants seeking to take advantage of these opportunities obviously require earned income. $^{3}$

Provincial social assistance programs are often described as "last resort" programs for people with little or no income from employment and with limited access to income-support programs such as EI and Q/CPP based on participation in the labour market. While these programs typically contain provisions for persons with disabilities, there is generally little beyond higher monthly benefits that distinguishes how the social assistance program provides for people with and without disabilities. In particular, these programs are focused on transitioning people back into employment - something that may not be realistic for many persons with disabilities. The AISH program in Alberta is an exception as are, to a lesser degree, programs in Ontario and BC.

\section{THREE PROGRAMS OF INCOME SUPPORT FOR PEOPLE WITH DISABILITIES}

\section{Assured Income for the Severely Handicapped (AISH)}

The AISH program in Alberta is unique in Canada for being completely separate from the provincial system of social assistance (known as Alberta Works). ${ }^{4}$ It is administered by a different ministry (Seniors and Community Supports as opposed to Employment and Immigration, the ministry that administers Alberta Works) and a strict eligibility requirement for receiving support under the AISH program is based on the question of whether the applicant suffers a disability that severely and permanently impairs his or her ability to find paid employment. In many respects, then, AISH has the characteristics of a public pension program.

1 Cameto, R., Marder, C., Wagner, M., and Cardoso, D. (2003). "Youth Employment.” NLTS2 DataBrief, 2(2), 1-6.

2 See Raymond Block, Mel Slomp, Scott Patten, Phillip Jacobs, Arto Ohinmaa, and Carolyn Dewa, "Disability Payments for Persons with Severe Mental Illness in Alberta, Canada," Psychiatric Services, Volume 60, No. 5, May 2009, pp. 686-688.

3 For a recent and detailed description of income programs and tax benefits available to Canadians with disabilities, see Michael Mendelson, Ken Battle, Sherri Torjman and Ernie Lightman "A Basic Income Plan for Canadians with Severe Disabilities,” Caledon Institute of Social Policy, November 2010.

4 Saskatchewan introduced the framework for a similar program in October 2009. Upon its introduction, the focus of the Saskatchewan Assured Income for Disability (SAID) program was to establish a program that is separate and unique from the provincial social assistance program (SAP). The level of income support, however, was initially the same as that available under SAP and the number of people enrolled in the new program was initially limited. Given the newness and limited scope of the program, we chose to not include it in our discussion. 
To be eligible to receive AISH payments, a person must have a "physical or mental impairment that substantially limits (the) ability to earn a livelihood and is likely to continue to affect that individual permanently." Of those receiving AISH payments, 47 percent have physical disabilities, 32 percent have mental illness disorders and 22 percent have cognitive disorders. Of those receiving AISH payments 12 percent are between 60 and 64 years of age, 53 percent are between 40 and 59 years of age, and 35 percent are aged between 18 and 39 . There are virtually no AISH recipients aged 65 years and over. In 2010, the AISH program was supporting approximately 40,000 cases (1.5 percent of Alberta's adult population). ${ }^{5}$

A person eligible to receive support through the AISH program currently receives a maximum financial benefit of $\$ 1,188$ per month. This compares to $\$ 583$ per month received by a single able person classified as "single employable" under Alberta Works. Those in the AISH program can supplement their income through employment though only a maximum amount of income can be earned before the monthly AISH payment is clawed back. For example, a single person on AISH can earn up to a maximum of $\$ 400$ per month without suffering a reduction in the monthly AISH payment. Income earned in excess of $\$ 400$ per month and up to $\$ 1,500$ is 50 percent exempt for a maximum employment income exemption of $\$ 950$ a month. As earned income increases, the AISH financial benefit shrinks. By the time earned income exceeds $\$ 2,138$ per month, the AISH benefit paid to a single person falls to zero. ${ }^{6}$

As well as the monthly financial benefit, AISH recipients and their families receive benefits in the form of premium-free Alberta Health Care Insurance, optical, dental work, emergency ambulance services, essential diabetic supplies and prescription drugs. As is the case with the programs in Ontario and $\mathrm{BC}$, those receiving AISH benefits are also subject to less restrictive asset requirements than those collecting regular social assistance benefits. The benefits provided to those in the AISH program, then, are multi-faceted. Benefits are in the form of direct income support and in the form of health benefits (income in kind).

\section{Ontario Disability Support Program (ODSP)}

The ODSP program, along with a revamped provincial social assistance program (known as Ontario Works), was introduced in 1998. The introduction of these programs was consistent with a promise from the provincial Progressive Conservative Party (elected in 1995) to move seniors and persons with disabilities from the provincial system of social assistance and to create a separate program of social assistance for persons with disabilities. ${ }^{7}$ The degree of separation between the ODSP program and the income-support program available to those without a disability is less apparent than in Alberta since in Ontario the two programs are both administered by the same ministry (Community and Social Services). The application procedures are, however, completely separate.

5 Information on the AISH program and the ODSP and PWD programs discussed below is available from Human Resources and Skill Development Canada, Social Assistance Statistical Report: 2007, available on-line at http://www.hrsdc.gc.ca/eng/publications_resources/social_policy/sasr_2007/page00.shtml. The approximate number of AISH cases in 2010 is from the 2009/10 Annual Report of the Ministry of Seniors and Community Supports.

6 The basic benefit paid to someone eligible for AISH is not dependent on family status. However, the clawback resulting from earning employment income is dependent on family status.

7 For a detailed description and discussion of the introduction of ODSP, see Harry Beatty, "Ontario Disability Support Program: Policy and Implementation," Journal of Law and Social Policy, Volume 13, 1999, pp 1-68. 
To be eligible to receive payments under the Ontario Disability Support Program (ODSP), a person must have "a substantial physical or mental impairment that is continuous or recurrent and expected to last one year or more. The impairment must substantially restrict the person in one or more activities of daily living." Relative to the AISH program, which emphasizes the ability of an applicant to find paid employment and the permanence of the disability, the eligibility criterion for ODSP is, on the face of it, somewhat less onerous.

Of those receiving ODSP payments, 11 percent are between 60 and 64 years of age, 55 percent are between 40 and 59 years of age, 30 percent are aged between 18 and 39 years of age and four percent of ODSP recipients are 65 and over. The vast majority of ODSP recipients are unattached single individuals and have been on the program for two years or more. ${ }^{8}$ As of July 2010, the ODSP program was funding 273,611 caseloads (three percent of Ontario's adult population). ${ }^{9}$

Unlike AISH, the monthly ODSP benefit varies by family status. A single person eligible to receive support through the ODSP currently receives a maximum financial benefit of $\$ 1,053$ per month. This compares to $\$ 572$ per month in social assistance received by an able, single and employable person under the Ontario Works program. Similar to the case in Alberta, there is a partial exemption for earned income equal to 50 percent of all earned income after three months on social assistance. ${ }^{10}$ As well as the monthly financial benefit, the ODSP provides supplemental health care benefits such as drug and dental coverage, assistance with the cost of vision care, medical transportation, diabetic supplies, assistive devices and mobility device repairs and batteries.

\section{Persons with Disabilities (PWD)}

In $\mathrm{BC}$, the provincial social assistance program is known as $\mathrm{BC}$ Employment and Assistance (BCEA). The current system originated with significant changes to social assistance programs introduced in 2002. Within this system, a person may receive a PWD (Person with Disability) designation and if such a designation is made, the person is relieved of the requirement to search for and retain employment in order to receive assistance. To be so designated, a person must be aged 18 years or older with a severe and confirmed mental or physical impairment that restricts their ability to perform daily living activities. The disability must be expected to continue for at least two years and the person must require an assistive device, the help or supervision of another person, or services of an assistance animal to perform daily living activities. As of July 2010, the PWD program was funding 74,730 caseloads (2.4 percent of BC's adult population). ${ }^{11}$

\footnotetext{
8 Reported in Time for a Fair Deal, Report of the Task Force on Modernizing Income Security for Working-Age Adults, May 2006.

9 A case refers to a single individual or a family unit receiving assistance. ODSP caseload data is from http://www.mcss.gov.on.ca/documents/en/mcss/social/reports/ODSP_EN_2011-05.pdf

${ }^{10}$ In Alberta, however, the first $\$ 400$ per month of earned income is not subject to claw back.

11 PWD caseload data is from http://www.mhr.gov.bc.ca/research/11/06-may2011.pdf
} 
Unlike the AISH program but like ODSP, the basic benefit provided to an individual with a PWD designation is dependent on family status. A single person designated PWD is currently eligible to receive a maximum financial benefit of $\$ 906.42$ per month. This compares to $\$ 610$ per month in social assistance currently available to an able, single person. An earnings exemption of $\$ 500$ per month is available to a PWD recipient following three months on assistance. As well as the monthly financial benefit, people receiving disability assistance are eligible for supports such as medical coverage that includes Medical Services Plan, no deductible for the provincial drug plan (PharmaCare) and other medical benefits such as dental and optical coverage. People with disabilities are also eligible for low-cost annual bus passes, a $\$ 35$ annual Christmas supplement and are exempt from time limits for receiving assistance. ${ }^{12}$

The Alberta, Ontario and BC programs of income support for persons with disabilities have similarities and differences. Alberta's AISH program is the nearest to a public pension. Basic benefits are unrelated to family status and the program is administered by a provincial ministry different from that tasked with administering the provincial social assistance program. What's more, the eligibility criteria are strict and emphasize the permanence of the disability. Basic benefits paid under Ontario's ODSP and British Columbia's PWD programs vary by family status and benefits are available to those with less than permanent disabilities. This makes these programs less like a public pension and more similar to social assistance programs intended to ease transition back into the work force. All three programs claw back payments when earned income is reported and the clawback is dependent on family status.

The design of Ontario's ODSP and British Columbia's PWD programs are similar to those in other provinces. What makes them somewhat different is that they are defined by separate legislation intended to recognize that public support for persons with disabilities ought to be fundamentally different from the support provided to those without disabilities. They are also, after Alberta's AISH program, the most generous in terms of basic income support.

\section{EVALUATING INCOME-SUPPORT PROGRAMS FOR PEOPLE WITH DISABILITIES}

As suggested by the metaphor of a safety net, social programs are designed to keep those in need from hitting a level of subsistence or standard of living below that provided by the "net." How high the social safety net should be set requires a judgement about how low the level of subsistence or standard of living of those in need should be before the government steps in to prevent undue suffering. In some countries, this value judgement is used to establish a "poverty line," a level of income below which people are deemed to be sufficiently poor that they should receive public assistance. As is true with any effort to define a value judgement in terms of dollars and cents, setting this poverty line is fraught with difficulty. It is perhaps for that reason that policymakers in Canada have avoided defining an "official" poverty line. However, analysts have proposed several measures of poverty. Some of these have been around for a number of years and some have, as befits a value judgement, sparked heated debate. A number of new measures of low income have been introduced quite recently and all vary to some degree in what they are intended to measure. We define and discuss four such measures below.

\footnotetext{
12 Retrieved from the BC Ministry of Social Development: http://www.hsd.gov.bc.ca/pwd.htm
} 
In what follows, we examine the respective amounts of income support provided by the AISH, PWD and ODSP programs to persons with disabilities and how this support has varied over time vis-à-vis various measures of poverty. By observing the level of support provided to those with disabilities relative to various measures of poverty, our examination provides some measure of understanding of what government policies aimed at persons with disabilities are trying to do. We offer suggestions for change and we estimate the cost of those changes.

\section{Two Broad Concepts of Poverty}

There are two ways of defining a reasonable or fair level of income support. Some advocate linking income support relative to some fraction of average earned income. Advocates of measures like these stress that those on income support should receive an amount sufficient to maintain a standard of living that is constant relative to that enjoyed by others in society. By this measure, if the average person in society enjoys an increase in his or her standard of living, the level of income support paid to those in need should also be increased so as to enable recipients to similarly enjoy an increase in their standard of living. The logic of this approach is based on the idea that what is deemed to be an adequate income changes over time. A standard of living deemed acceptable 100 years ago (no indoor plumbing, limited access to health care, etc.) might now be viewed as unacceptable. Thus, income support should increase with the standard of living of the average person in society. Opinions vary as to what fraction of the average person's income is an appropriate level of income support.

Other analysts prefer an absolute measure whereby the level of income support reflects the cost of maintaining a certain minimum standard of living. Under this approach, income support increases only if the cost of maintaining a defined standard of living increases; there is not necessarily a connection between the standard of living of the average person in society and the person on social assistance. The logic of this approach is that income support should be sufficient only to guarantee access to life's necessities. Again, opinions vary as to what defines life's necessities.

Considerations of the arguments for and against relative versus absolute measures of social assistance are beyond the scope of this paper. What we will do instead is more modest. We will briefly define five measures of poverty that are used in Canada. We will show that some are more heavily weighted toward the idea of an absolute measure of poverty while others lean more toward a relative measure. These measures therefore provide measuring sticks against which opinions about the appropriate level of income support can be measured. After providing these brief descriptions, we will show how the level of income support provided by the AISH, ODSP and PWD programs compare to these various measures of poverty.

\section{Five Specific Measures}

The Fraser Institute has published poverty lines developed by economist Christopher Sarlo. ${ }^{13}$ These measures of poverty are designed to measure the income required to meet only the most basic needs. Sarlo defines a basket of goods and services that includes shelter, food, clothing, personal hygiene needs, health care, transportation and a telephone connection.

13 See Christopher Sarlo, Measuring Poverty in Canada, The Fraser Institute, July 2001 and What is Poverty? Providing Clarity for Canada, The Fraser Institute, May 2008. 
The basket consciously excludes any goods or services that go beyond meeting very basic needs and is purposely designed to measure only the income required to ensure physical survival. The measure differs by province because the costs of items in the basket differ by location. The measure is determined for a base year and then adjusted over time by the AllItems Consumer Price Index (CPI) for that province. ${ }^{14}$ Because it is adjusted for inflation, this measure defines a measure of income support that is constant in real terms. That is to say, it defines a level of income that will buy the same quantity of goods and services year in and year out. The quantity of goods and services this income can provide does not change with the general standard of living in society. It is, then, an absolute measure. In our discussion below, we will refer to this as the Sarlo measure.

The Market Basket Measure (MBM) was developed by Human Resources and Skills Development Canada in response to a perceived need on the part of provincial and territorial governments to have an agreed-upon measure of low income. ${ }^{15}$ Like the Sarlo measure, the MBM is an absolute measure as it defines a basket of goods and services that does not change with shifts in the general standard of living in society. The income required to purchase this basket of goods and services is adjusted to reflect changes in prices. Thus the MBM defines a level of income that will buy the same quantity of goods and services year in and year out.

The MBM includes recreation items, transportation (including an automobile for inhabitants of rural areas) and other similar items in its basket of goods. This reflects a judgement that an element of poverty is the extent to which the impoverished suffer social exclusion. Thus the measure recognizes that anyone whose income falls below this level is unable to meet basic needs including the ability to purchase entertainment and enjoy recreational activities. ${ }^{16}$ This adjustment therefore takes the MBM a step beyond the Sarlo measure of basic needs. Like the Sarlo measure, the MBM differs by province.

For the purpose of making international comparisons, the Low Income Measure (LIM) is the most commonly used method for setting the poverty line. In simple terms, the LIM is a fixed percentage (50 percent) of median adjusted household income. Since the LIM is strictly based on income distribution, researchers can compare low income in Canada with low income in

14 Adjusting this measure over time using the All-Items CPI is not ideal. Sarlo's basket of basic needs is different from the basket of goods contained in the All-Items CPI. It would be preferable to track the prices of the items in Sarlo's basket and create a price index specific to that particular basket of goods.

15 See Human Resources and Skills Development Canada, Low Income in Canada: 2000-2007 Using the Market Based Measure - August 2009, available on-line at: http://www.hrsdc.gc.ca/eng/publications_resources/research/categories/inclusion/2009/sp-909-07-09/page00.shtml

16 Specifically, the MBM is based on the definition that a family unit is considered to be in a situation of low income when its disposable income available for consumption falls below the cost of a basket of goods and services determined on the basis of its community or a community of the same size. The specific items in the market basket are identical for each geographical location but their proportions vary somewhat. The major adjustment for geographic difference is made through the different purchasing costs of the items in the MBM basket. The price index used to adjust the MBM is a weighted average of the changes in price of each of the items in the basket. Thus the MBM grows over time at a rate different from the provincial All-Items CPI. Like all market basket measures, the MBM suffers from the fact that its basket of goods may not represent the consumption choices of a specific population, in this case, persons with disabilities. 
any country in which an income survey is conducted. Statistics Canada has provided measures of the LIM since the early 1990s. Although a separate LIM for each province could conceivably be defined, only a national version is currently available. ${ }^{17}$ Since the median household income rises more quickly than inflation (indicating a rising standard of living for the median household) and since LIM is tied to household income, LIM rises faster than inflation. LIM is therefore a measure of income support that enables recipients to buy more goods and services over time and so enjoy a rising standard of living. It is, then, a relative measure of low income.

Researchers at Statistics Canada have recently introduced a variation on the LIM that "anchors" the measure of poverty to a standard of living at a point in time. That adjustment produces a version of the LIM that is an absolute measure. Having chosen a base year, this version of the LIM is adjusted over time by the All-Items Consumer Price Index (CPI) for that province. In our discussion below, we will identify this version of LIM as the fixed LIM and the original version as the floating LIM. ${ }^{18}$

The fixed LIM is adjusted for inflation and so defines, like the Sarlo and MBM measures, a level of income that will buy the same quantity of goods and services year in and year out. It differs from the Sarlo and MBM measures by the level of real (inflation-adjusted) income it defines. Because LIM is a national measure, while the MBM and Sarlo are province-specific, there is some variation across provinces with respect to their relative sizes. Measured in real terms, in Ontario and BC the fixed LIM measures a level of income greater than the MBM, which in turn defines a level of income significantly greater than that defined by the Sarlo measure. In Alberta the fixed LIM and the MBM are very close in size and both are significantly greater than the Sarlo measure.

All these measures of poverty - floating LIM, fixed LIM, the MBM and the Sarlo measure are available for different sized families. This reflects the idea that there are economies of scale to living with others that allows, for example, two people together to subsist more cheaply than two people living apart. In our discussion below, we use versions of these measures appropriate for a single adult.

Our list of poverty measures defines a hierarchy from a strongly absolute measure of basic needs (Sarlo), to an absolute measure of a broader set of needs (MBM), to a relative measure anchored to a standard of living at a point in time (fixed LIM), to a relative measure that varies continuously with the standard of living of the average Canadian (floating LIM). ${ }^{19}$

\footnotetext{
17 Statistics Canada CANSIM database, series v5267546.

18 Because they are adjusted over time using the provincial All-Items CPI, fixed LIM and the Sarlo measure vary in the same way over time. The MBM is adjusted over time using a different price index (see footnote 14) and so varies somewhat from movements in the fixed LIM and Sarlo measures.

19 Notable by its absence from our list of poverty measures is the Low Income Cut-Off (LICO). While popular with the media and some advocacy groups, Statistics Canada has been consistent in its disclaimers that the LICO should not be considered a measure of poverty. Essentially, LICO defines someone as being in "straightened circumstances" if he or she were required to spend 70 percent or more of income on food, shelter and clothing. The 70 percent figure is completely arbitrary and was determined by identifying that the average family spent 50 percent of income on food, shelter and clothing. We judge the MBM and the LIM to be superior measures. In 2007, the LICO measure was very close in value to the floating LIM measures.
} 
To this list of poverty measures, we add the amount of income support that the federal government provides to retired Canadians who have no other source of income. The federal government provides Old Age Security (OAS) and the Guaranteed Income Supplement (GIS) to all retired Canadians. The OAS payment is not sensitive to income. The GIS varies by the amount of other income available from private savings, the Q/CPP, employment or rental income, etc. Both the OAS and the GIS are adjusted for inflation using the All-Items CPI for Canada. ${ }^{20}$ Thus these amounts are absolute measures similar to the fixed LIM. The amount of OAS plus the amount of GIS payable to someone with no other income defines what the federal government has identified as an income sufficient for someone unable to work to meet basic requirements. To our minds, this makes the sum of these two sources of income - what we will identify as OAS+GIS in our discussion below - a useful metric against which to compare the amount provincial governments judge to be an income sufficient for a person with a disability to meet basic requirements.

\section{INCOME SUPPORT AND MEASURES OF POVERTY}

In this section we offer alternative ways of forming a judgement regarding the adequacy of income support provided to persons with disabilities. We will consider each province's program in turn starting with Alberta's AISH program. Having started in 1979, AISH is the oldest of the three.

Before proceeding with this discussion, we feel it is important to emphasize that no measure of poverty is perfect. All have strengths and weaknesses and some provide useful information relevant for some questions while others do so for other questions. Just like everyone else, we do not have a measure of poverty upon which all can agree. As noted in the introduction, to a large extent any measure reflects value judgements that cannot be judged to be either wrong or right. We compare the levels of income support provided to those with disabilities to a variety of poverty measures for just that reason. The only measure of poverty we feel comfortable with saying sets a level of income below which all would agree income support should not fall is Sarlo's measure of basic needs.

\section{The Alberta Program}

Figure 1 shows the history of the size of the monthly AISH financial benefit since 1993 in comparison to the five measures of poverty we discussed earlier. ${ }^{21}$ We choose 1993 as a starting point for two reasons. First, it facilitates comparison to ODSP and PWD benefits which began in 1998 and 2002 respectively. Second, this was the beginning of a period of significant budget cutbacks in Alberta and so starting with that year enables us to offer some insights into the effect government financial difficulties have on those who rely on government support.

20 See Human Resources and Skills Development Canada, The CPP and OAS Stats Book 2010, available on-line at http://www.servicecanada.gc.ca/eng/isp/statistics/pdf/statbook.pdf. To the extent that provincial rates of inflation differ from the national rate, OAS+GIS payments either grow or shrink in real terms. Over long periods of time we would expect this to be a relatively small problem

21 Sources: AISH financial benefit from Alberta Human Resources and Employment. When benefits change during a year, we report the weighted average of the monthly payment before and after the change. This is true as well for Figures 2 and 3 below. 
FIGURE 1: AISH Payment and Alternative Measures of Poverty

Nominal dollars per month

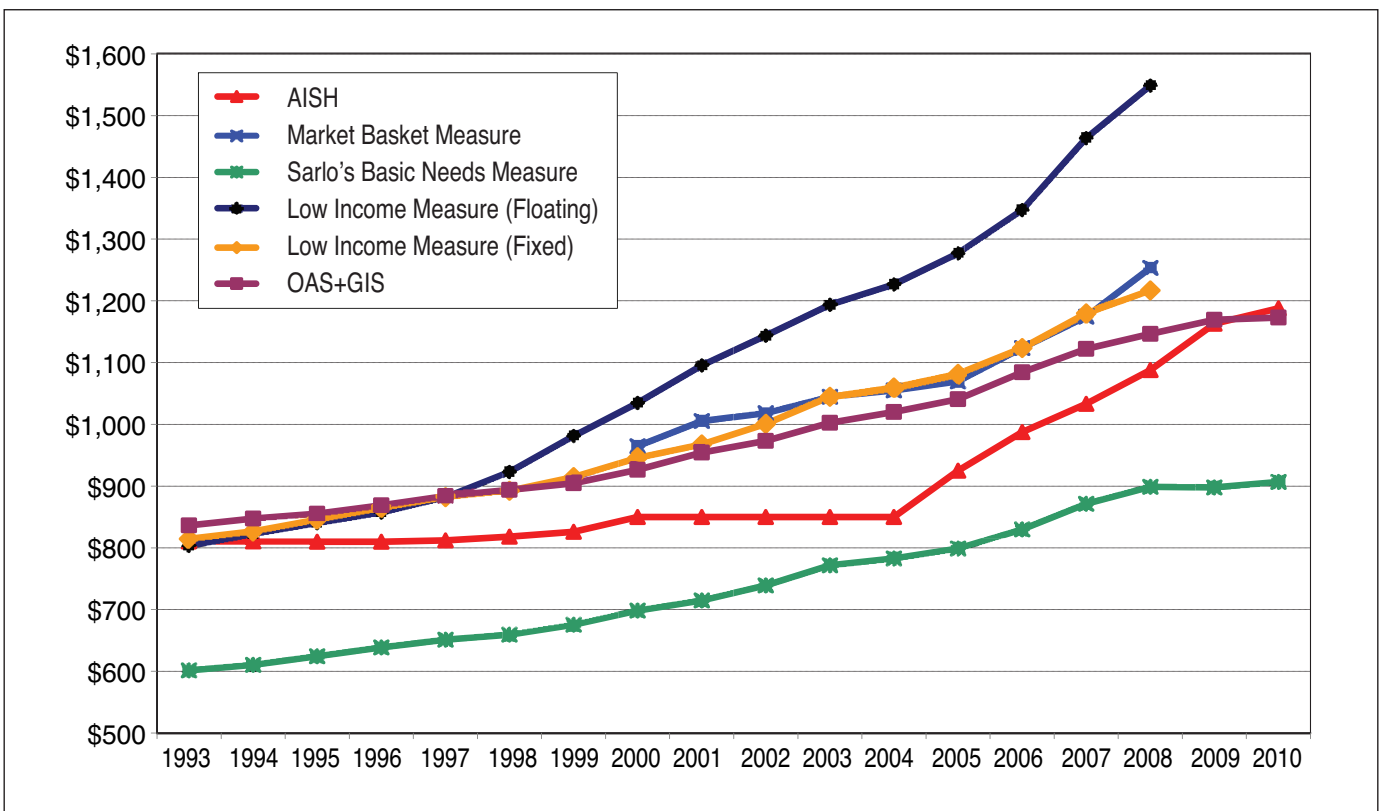

All of the lines in Figure 1 measure incomes in nominal dollar terms. Thus the line showing the history of AISH payments since 1993 reports the actual payments made to AISH recipients. ${ }^{22}$ In 1993, a person in the AISH program received $\$ 810$ per month. This was bumped up to $\$ 818$ four years later on July 1,1997 , and was increased again two years later to $\$ 850$ per month on October 1, 1999, where payments remained until 2005..$^{23}$ Beginning on April 1, 2005, AISH payments have been increased more or less regularly so that by April 2009 the monthly benefit was equal to $\$ 1,188$ per month. Benefits have not been increased since that date.

Nominal dollar values are not a good measure of the true generosity of AISH payments. This is because the cost of living has increased since 1993. As a result, a dollar today buys fewer goods and services than it did then. To understand the effects of inflation on AISH payments, it is useful to compare them to the payments made by the federal government to low-income seniors, which are identified by the line called OAS+GIS. As discussed earlier, OAS+GIS payments are regularly adjusted by the national CPI to ensure those payments keep up with inflation.

22 Our measure of the income available to AISH recipients does not include federal and provincial tax benefits available to low-income Canadians. In Alberta the quarterly GST credit payable to an AISH recipient is currently $\$ 92.30$ or $\$ 23.08$ per month. The benefit of tax credits requires, of course, that one file a tax return. It is noteworthy that concern about the rate of take up on these benefits has prompted some advocacy groups to introduce programs to aid beneficiaries to access benefits. Rather than speculate on what the take-up rate might be and so what the average AISH recipient might receive, we have chosen to cite gross income figures. Where appropriate, we point out the implication of these tax credits.

${ }^{23}$ When benefits change during a year, we report the weighted average of the monthly payment before and after the change. This is true as well for Figures 2 and 3 below. 
In 1993 AISH payments were only slightly lower than OAS+GIS payments ( $\$ 810$ versus \$836). Over time, OAS+GIS payments were adjusted upward by the rate of inflation. AISH was not. The result was a rapid divergence between the two series. By 2004, AISH payments had increased to $\$ 850$ while OAS+GIS had grown to $\$ 1,020$. This divergence reflects the effects of inflation; whereas OAS+GIS kept up with inflation, AISH did not. To put it differently, while a low-income senior could purchase the same quantity of goods and services in 2004 as she had in 1993, a recipient of AISH payments suffered a significant decline in the amount of goods and services she could purchase. ${ }^{24}$

The Alberta government's commitment after 2004 to make more or less regular increases in the size of the AISH benefit pushed the value of benefits upward. Indeed, they increased faster than the rate of inflation so that by 2010 the monthly AISH payment was again equal to the federal OAS+GIS payment. By 2010 the monthly AISH payment could once again buy the same quantity of goods and services that it had in 1993. In between these two years, however, the purchasing power of the monthly AISH payment was allowed to deteriorate to a significant extent.

Another way of evaluating the generosity of the monthly AISH payment is to compare its evolution to the size of the Sarlo measure. Like OAS+GIS, the Sarlo measure defines an absolute standard of living that is adjusted for inflation. ${ }^{25}$ Both measures define an amount of income required to maintain a constant standard of living. They differ only in that the Sarlo measure defines a level of income necessary to meet life's bare necessities while OAS+GIS defines a level of income that allows for a significantly higher living standard. Because the government of Alberta did not choose to adjust the monthly AISH payment by the rate of inflation, the amount of goods and services that payment could buy fell steadily after 1993 so that by 2004 , the AISH benefit was able to buy just slightly more than the amount defined by the Sarlo measure. In other words, the monthly AISH payment was allowed to deteriorate to a point that it was only just sufficient to meet life's bare necessities. Since 2004, to the government's credit, the monthly AISH payment was increased back to a level significantly above the Sarlo measure.

The remaining lines in Figure 1 define the other measures of poverty discussed above: the MBM, fixed LIM and floating LIM. Data on these measures are available only to 2008. The monthly AISH payment lies everywhere below these alternative measures of poverty despite beginning our period of analysis close in value to each of them. A major reason for this is that the monthly AISH payment was not indexed for inflation and was not increased significantly between 1993 and 2004. By the time the government responded, the purchasing power of AISH had fallen well below these measures of poverty. But even following a rapid increase in the monthly benefit that restored AISH's 2010 purchasing power to its 1993 levels, it remained

${ }^{24}$ While over the period 1993-2004 AISH payments increased by 5 percent (from $\$ 810$ to $\$ 850$ ), Alberta's CPI increased by 30 percent. The real, or inflation-adjusted, value of the monthly AISH payment fell by just under 20 percent.

25 As discussed earlier, the Sarlo measure is adjusted by the All-Items CPI for Alberta whereas the OAS+GIS measure is adjusted by the All-Items CPI for Canada. To the extent rates of inflation differ in Alberta from what is experienced in the rest of country, the difference in the Sarlo and the OAS+GIS measures will change. This is not a large effect. 
noticeably below the values of the LIM and MBM. ${ }^{26}$ This is particularly true of the floating LIM, which is a relative measure of poverty. The gap between AISH and the floating LIM is an indication of the extent to which the income of AISH recipients has fallen relative to the average earned income of the rest of Albertans.

It is reasonable to conclude that for a long time, the government of Alberta's support for persons with disabilities failed to protect the latter from the effects of inflation, causing that support to fall noticeably behind all of our measures of poverty except the Sarlo measure of basic needs, a level of income which AISH payments nonetheless approached. It is fair to ask whether the government's focus on deficit reduction after 1993 was responsible for the failure to adjust AISH for increases in the cost of living. If this was the reason, it is certainly the case that those relying on AISH for income support shared in the burden of that effort. To its credit, beginning in 2004 the government of Alberta began a concerted effort to increase the income of AISH recipients. By 2010, AISH payments had returned to a level that the federal government deems appropriate for low-income seniors. However, payments remain below that which supporters of the LIM and MBM measures would deem appropriate. ${ }^{27}$ Finally, it is worth noting that with a return to budget deficits, the government has chosen to hold the monthly AISH payment at its 2009 level and so again chosen to allow inflation to eat away at the purchasing power of disabled persons' income.

\section{The Ontario Program}

Figure 2 shows how Ontario Disability Support Program (ODSP) payments to a single person with no children have changed over time relative to the various measures of poverty discussed above. ${ }^{28}$ The ODSP was introduced in 1998 during a period of provincial fiscal restructuring under Premier Mike Harris (elected in 1995). Perhaps for that reason, the monthly ODSP payment remained constant in nominal dollars from inception until 2004. Since 2004 the monthly payment has increased albeit very slowly.

${ }^{26}$ It is interesting that income support falls below MBM for two reasons. One is that the government of Alberta uses the percentage of all Albertans living at or above the MBM as one of its performance measures. The target for the government is to rank in the top three provinces in this regard. The other is that a committee reporting to the provincial legislature in 2001 recommended tying the level of income support provided to those unable to work to the MBM. See MLA Committee to Review Low-Income Programs, Low-Income Review: What we Heard, November 2001.

27 Those preferring the relative measure of poverty, as measured by the floating LIM, for example, would of course be least happy with the current level of AISH payments. Even they, however, would agree that after a long period of poor support, the government of Alberta has exhibited a stronger record since 2004. Indeed, it is worth noting that since 2004 the slope of the line showing AISH payments is almost parallel to that showing the floating LIM. This indicates that since 2004, the government has kept AISH payments at a more or less constant fraction of median income.

28 As noted earlier, ODSP payments vary by family status. We focus on a single person with no children to facilitate comparison to the AISH program. We continue to present the gross income payable to someone eligible for ODSP payments. A single ODSP recipient with no children is currently eligible for a quarterly GST credit of $\$ 84.66$ and a quarterly Ontario Sales Tax Credit of $\$ 65.00$. These credits, if applied for and received, provide an additional $\$ 37.42$ per month. 
As we discussed in the previous section, holding payments constant in nominal dollars means causing the purchasing power of the monthly ODSP payment to fall, forcing recipients to get by on an income that can buy a smaller amount of goods and services. Once again, a comparison to the payments made to low-income seniors (OAS+GIS) - payments that are indexed for inflation and so enable recipients to buy the same quantity of goods and services over time - is useful for understanding the effects on inflation. In 1998, the monthly ODSP payment was just above the OAS+GIS payment ( $\$ 930$ versus $\$ 893$ ) but the effect of inflation quickly caused the OAS+GIS monthly payment to pass ODSP. Despite the slow growth in the size of the ODSP payment since 2004, the gap between ODSP and OAS+GIS has continued to grow, indicating those increases have been insufficient to keep up with inflation.

\section{FIGURE 2: ODSP Payment and Alternative Measures of Poverty}

Nominal dollars per month

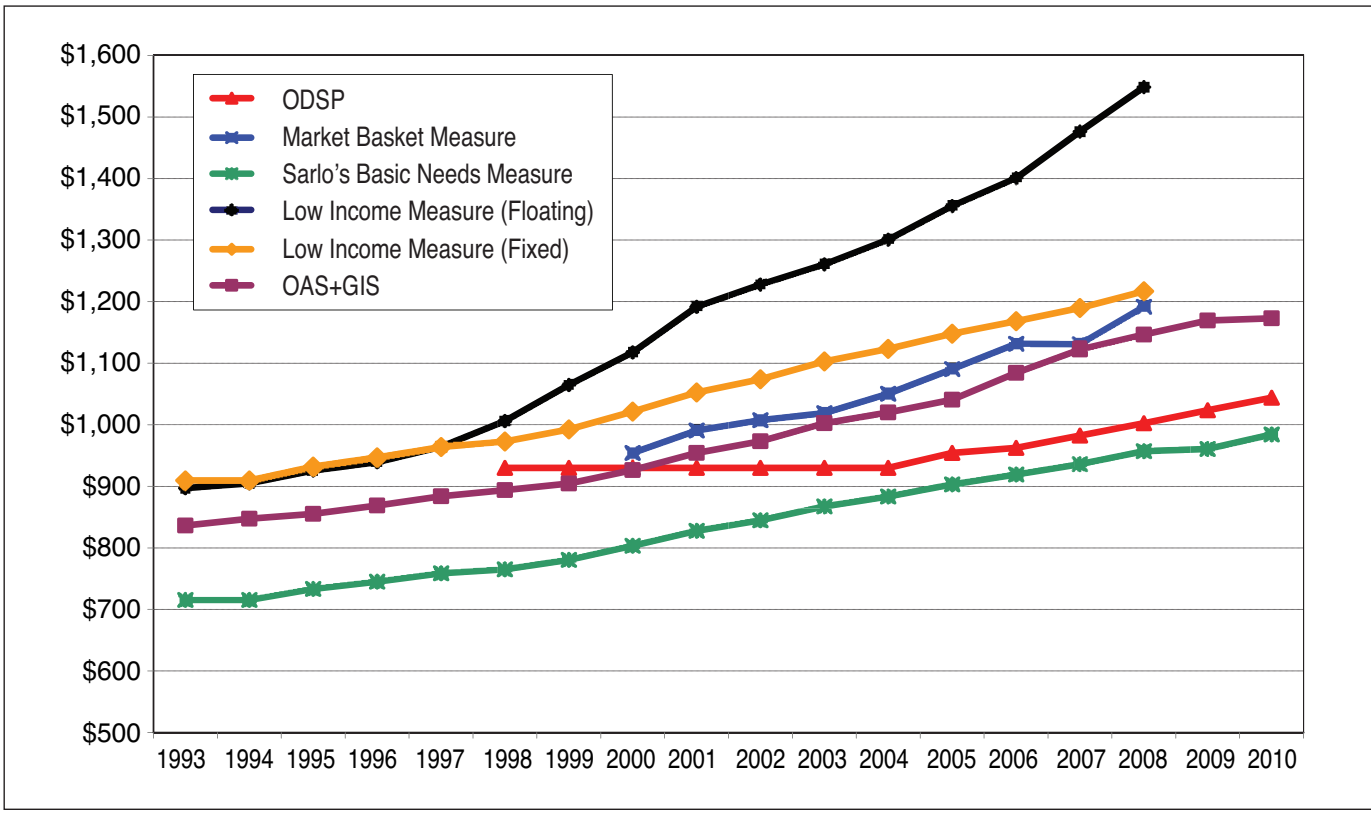

The Sarlo measure is considerably higher in Ontario than in Alberta. This reflects the higher cost in Ontario of purchasing the bare necessities that comprise the Sarlo basket of goods and services. This, plus the slower growth of the ODSP versus the AISH monthly payment has meant that income support for persons with disabilities in Ontario has remained far closer to the Sarlo measure in Ontario than in Alberta. Whatever one's opinion about how adequate it is, clearly the monthly AISH payment enables Albertans with disabilities to enjoy a standard of living that is considerably higher than that enjoyed by disabled persons living in Ontario. Were the ODSP monthly payment paid in 2010 set at 122 percent of the Sarlo measure as it was in 1998 , it would have been $\$ 152$ per month higher than its actual value of $\$ 1,044$. 


\section{The BC Program}

Figure 3 shows how payments to those eligible for the Persons With Disabilities (PWD) designation under the BC Employment and Assistance (BCEA) program have changed over time relative to the various measures of poverty discussed above. ${ }^{29}$ Payments to citizens in British Columbia suffering with a disability fall below all of our measures of poverty. The PWD monthly payment has averaged 94 percent of the monthly value of the Sarlo measure of the cost of purchasing the bare necessities in BC. ${ }^{30}$ The monthly PWD payment has never been set close to the level of income that the federal government deems appropriate to provide to low-income seniors. Were the PWD monthly payment paid in 2010 set equal to the OAS+GIS monthly payment, it would have been \$267 per month higher than its actual value of $\$ 906$.

\section{FIGURE 3: PWD Payment and Alternative Measures of Poverty} Nominal dollars per month

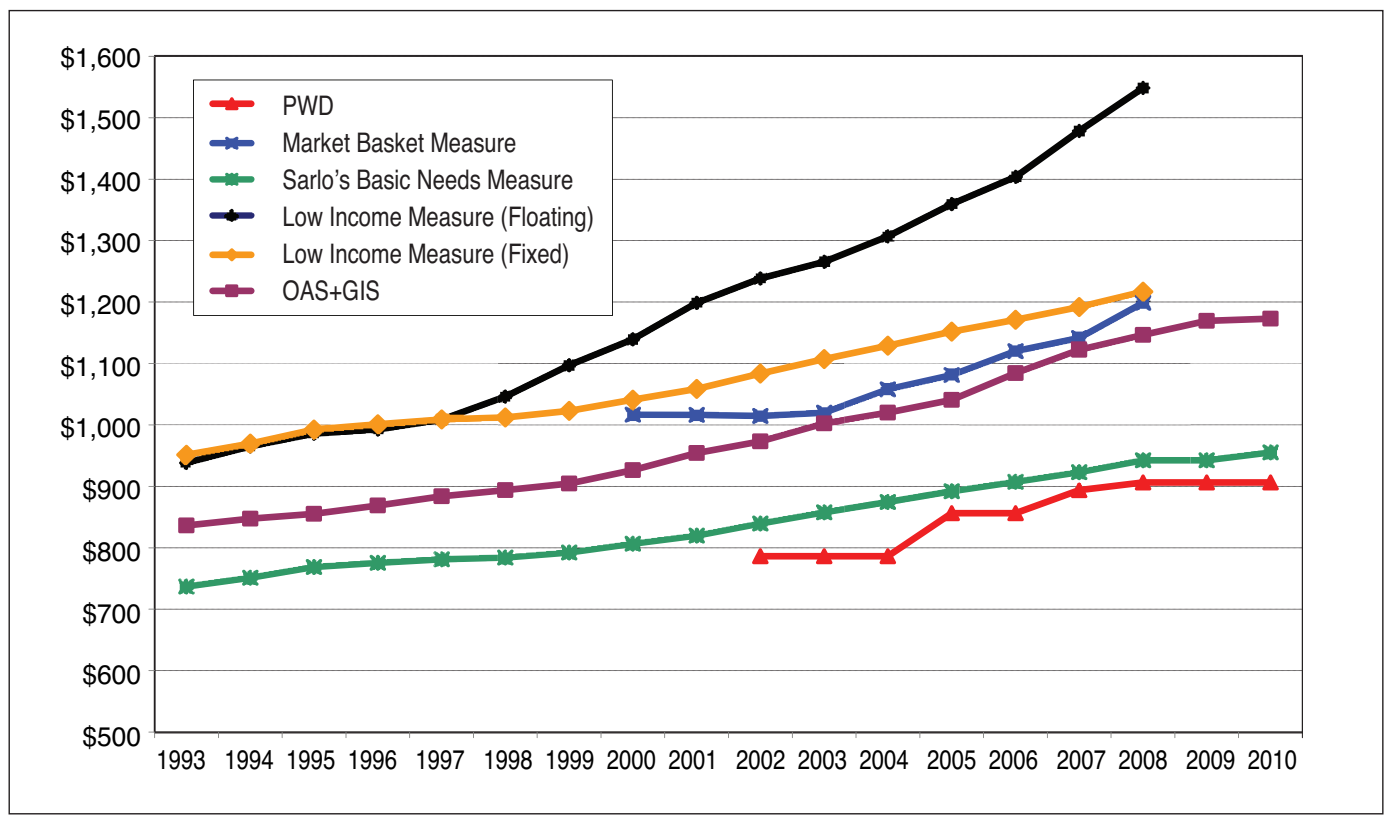

Growth in the floating LIM gives an indication of the rate of growth in the standard of living of the average person. Of the three provincial programs, PWD monthly payments have fallen the furthest below the floating LIM and by 2008 the monthly payment was equal to just 59 percent of that measure. This compares to ODSP at 65 percent and AISH at 70 percent of the floating LIM. The graphs suggest that these percentages will continue to fall over time and will fall fastest in British Columbia.

${ }^{29}$ Like ODSP, PWD payments vary by family status. We again focus on a single person with no children to facilitate comparison to the AISH program. Our figures show the gross income payable to someone eligible for the PWD designation in BC. A single PWD recipient with no children is currently eligible for a quarterly GST credit of $\$ 76.38$, a quarterly BC HST Credit of $\$ 26.25$ and a BC Low Income Climate Action Tax Credit of $\$ 57.50$. These credits, if applied for and received, provide an additional $\$ 40.03$ per month

30 Adding the amount of quarterly tax benefits to the PWD benefit would, in 2010, have increased total after-tax monthly income to $\$ 946.03$, which is 99 percent of the Sarlo measure (\$955). 


\section{THE COST OF A MODEST PROPOSAL}

Increasing income support to persons with disabilities is an expense for the government and so requires tax increases or cuts to spending in other government programs. Taxpayers expect their governments to be aware of the cost of its programs and should expect them to report the cost of policy changes. What might the cost of changes in income support for disabled persons be?

Suppose we take as a given that Canadians view the monthly income provided to poor seniors by the federal government as a reasonable level of income support. In defence of this suggestion, we note that the fairly modest monthly increases debated by the major political parties in the 2011 federal election suggest this to be a reasonable first approximation, otherwise voters would have demanded larger increases and the parties would have been anxious to respond to those demands. ${ }^{31}$ Now suppose we think it reasonable that someone who is unable to work due to a disability and who has no other source of income ought to receive a level of income support similar to that provided to a poor senior. What would that cost? ? $^{32}$

As noted earlier, in July 2010, the number of ODSP caseloads was 273,611. In 2010, the gap between the monthly ODSP payment and the amount paid by the federal government to poor seniors (our OAS+GIS amount) was $\$ 129.16$. The cost of increasing the monthly ODSP payment by that amount in 2010 would therefore have been $\$ 424$ million.

How large is that? It is an amount equal to 4.9 percent of the 2010 budget of the Ontario Ministry of Community and Social Services, the ministry responsible for ODSP. It is an amount equal to 0.7 percent of the total tax revenues and 0.5 percent of all revenues collected by the Government of Ontario in fiscal year 2009-10. ${ }^{33}$

In July 2010, the number of PWD caseloads in British Columbia was 74,730. In 2010, the gap between the monthly PWD payment and the amount paid by the federal government to poor seniors (our OAS+GIS amount) was $\$ 266.57$. The cost of increasing the monthly PWD payment by that amount in 2010 would therefore have been $\$ 240$ million.

That amount is equal to 8.9 percent of the budget of the BC Ministry of Housing and Social Development, the ministry responsible for social assistance. It is an amount equal to 1.4 percent of the total tax revenues collected by the province and 0.6 percent of all revenues collected by the Government of BC in 2009-10. These amounts are larger than the same calculations in Ontario because the PWD benefit is so low.

\footnotetext{
${ }^{31}$ Although the numbers changed somewhat during the campaign, all parties coalesced around a promise to commit an additional $\$ 700$ million or so to increasing the monthly GIS benefit. These promises amount to an increase of about three percent in the income support provided to poor seniors in 2010.

32 Our estimates of cost are based on an assumption that the number of benefit recipients is not affected by the change in benefit levels. One should expect that assumption to be violated resulting in somewhat higher costs than we calculate. For evidence on this see Michele Campolieti, "Moral Hazard and Disability Insurance: On the Incidence of Hard-to-Diagnose Medical Conditions in the Canada/Quebec Pension Plan Disability Program," Canadian Public Policy, Vol. 28, No. 3, pp 419-441, September 2002.

33 Source: 2011 Ontario Budget. In 2009-10 the government collected \$64,931 million in tax revenue and \$95,793 million in all revenues. The budget of the Ministry of Community and Social Services was $\$ 8,621$ million.

34 Source: Budget 2011, Government of British Columbia. In fiscal year 2009-10 the province collected \$17,102 million in tax revenue and $\$ 37,521$ million in total revenue. The Ministry of Housing and Social Development's budget was $\$ 2,679$ million.
} 
If $\mathrm{BC}$ citizens consider that investment too large, or if the government feels that matching the OAS+GIS benefit should be accomplished gradually, then a first step might be to increase the monthly PWD benefit to equal the income Sarlo identifies as necessary to meet basic needs in BC, $\$ 955$ in 2010. That would cost $\$ 44$ million, an amount equal to only 1.6 percent of the ministry's budget in 2010 and a negligible fraction of provincial revenue.

In Alberta, the monthly AISH benefit was slightly above the OAS+GIS benefit in 2010. The government of Alberta, then, need not spend additional amounts to meet the goal of providing persons with disabilities with the same income support provided to poor seniors. We noted earlier, however, that the government of Alberta has not increased the monthly AISH payment since April 2009. Thus it has for two years allowed inflation to reduce the purchasing power of the benefit. This saved the government $\$ 7.4$ million in 2010, an amount equal to less than 0.5 percent of the budget of the Alberta Ministry of Seniors and Community Supports. By any measure it is a small amount for the Government of Alberta.

\section{CONCLUDING COMMENTS}

Three provinces - Alberta, Ontario and British Columbia - have in place legislation recognizing that people with disabilities deserve an income-support program that differs from that available to the unimpaired. In addition to non-pecuniary benefits, these programs provide a level of income support significantly greater than that available to someone without a disability. The details of the three programs differ, with Alberta's AISH program coming closest to representing a public pension plan for those with permanent disabilities. The programs in Ontario and $\mathrm{BC}$ are more closely aligned with the social assistance programs in other provinces, but stand apart from those programs by virtue of legislation designed to distinguish between persons with disabilities and those without.

We have shown how the monthly payments to persons with disabilities have changed over time and provided data on a number of measures of poverty. With this information readers can evaluate government support for people with disabilities using the measure of poverty that best represents their own value judgement concerning what that level of support should be. We have stressed that all of these measures of poverty have strengths and weaknesses. There is no single measure of poverty upon which all can agree and any measure of poverty reflects value judgements that cannot be judged to be either wrong or right. We compare the levels of income support provided to disabled persons to a variety of poverty measures for just that reason. For these reasons, we have avoided imposing our own views on what the appropriate level of income support ought to be. We will, however, offer three final observations.

The first has to do with the effects of inflation. Allowing inflation to reduce the purchasing power of disability payments (or, indeed, any income-support payment) is simply poor public policy. Good public policy is made by policymakers who are forthright in stating and holding up to comment their judgments about what the appropriate level of income support offered to the disadvantaged and vulnerable in society should be. Having made that choice, citizens should expect their governments to maintain that level of support and not allow it to be changed by inflationary stealth. An obvious solution to this problem is to index disability payments to the cost of living. It is standard practice for all Canadian governments to index tax 
brackets for inflation to avoid imposing costs on taxpayers due to inflation. It seems to us that those on social assistance deserve similar consideration. This is the federal government's policy with respect to the income support provided to poor seniors. There exists, then, a working model of how to implement this policy and so it would not seem a difficult one for provincial governments.

Our second observation is that there is one measure of poverty we feel comfortable in suggesting is a level of income below which all would agree income support should not fall: Sarlo's measure of basic needs. It is for that reason that the level of support provided to disabled persons in $\mathrm{BC}$ is disturbing; it falls slightly below that measure of income required to meet basic needs. Support in Ontario is above the income required to meet basic needs though not by very much. In both provinces income support for disabled persons has remained more or less constant relative to the Sarlo measure since 2004. This suggests that since 2004, those governments have judged the Sarlo measure to be a relevant standard for determining the level of support; one thinks it should be a bit (currently $\$ 69$ per month) above while the other thinks it should be a bit ( $\$ 49$ per month) below. ${ }^{35}$ Although we have not made similar calculations for other provinces, we emphasize that Ontario and BC provide income support in excess of that provided in other provinces. The Government of Alberta allowed inflation to reduced income support to approach the Sarlo measure in 2004, but to its credit has since pulled support well above (by $\$ 281$ per month in 2010) that level.

Our final observation is that Canadians seem to accept the level of income support provided to poor seniors as a reasonable level to offer someone unable to work and with no other source of income. We think that this seems to be a level of income support most Canadians would support as appropriate for persons with disabilities. Others may (and likely will) disagree with that assessment and advocate for a still higher level of income that would take support closer to one of the other low-income measures we have described.

35 If we account for the quarterly tax benefits defined earlier, monthly ODSP benefits are currently $\$ 106$ above the Sarlo measure while monthly PWD benefits are $\$ 9$ below. We recognize that the non-pecuniary benefits made available to AISH, ODSP and PWD recipients have value. A full accounting of the generosity of these programs relative to the Sarlo measure would need to put a dollar value on these benefits and recognize that recipients with different family characteristics enjoy different amounts of support. Recognition would also need to be paid to the fact that not all those who are eligible for these benefits actually access them. Finally, we should note that poor seniors, to whom we suggest making income comparisons, are also recipients of these tax benefits and also of non-pecuniary benefits like subsidized health benefits and low-cost transit fares. 



\section{ABOUT THIS PUBLICATION}

The School of Public Policy Research Papers provide in-depth, evidence-based assessments and recommendations on a range of public policy issues. Research Papers are put through a stringent peer review process prior to being made available to academics, policy makers, the media and the public at large. Views expressed in The School of Public Policy Research Papers are the opinions of the author(s) and do not necessarily represent the view of The School of Public Policy.

\section{OUR MANDATE}

The University of Calgary is home to scholars in 16 faculties (offering more than 80 academic programs) and 36 Research Institutes and Centres including The School of Public Policy. Under the direction of Jack Mintz, Palmer Chair in Public Policy, and supported by more than 100 academics and researchers, the work of The School of Public Policy and its students contributes to a more meaningful and informed public debate on fiscal, social, energy, environmental and international issues to improve Canada's and Alberta's economic and social performance.

The School of Public Policy achieves its objectives through fostering ongoing partnerships with federal, provincial, state and municipal governments, industry associations, NGOs, and leading academic institutions internationally. Foreign Investment Advisory Committee of the World Bank, International Monetary Fund, Finance Canada, Department of Foreign Affairs and International Trade Canada, and Government of Alberta, are just some of the partners already engaged with the School's activities.

For those in government, The School of Public Policy helps to build capacity and assists in the training of public servants through degree and non-degree programs that are critical for an effective public service in Canada. For those outside of the public sector, its programs enhance the effectiveness of public policy, providing a better understanding of the objectives and limitations faced by governments in the application of legislation.

\section{DISTRIBUTION}

Our publications are available online at www.policyschool.ca.

\section{DISCLAIMER}

The opinions expressed in these publications are the authors' alone and therefore do not necessarily reflect the opinions of the supporters, staff, or boards of The School of Public Policy.

\section{COPYRIGHT}

Copyright (C) 2011 by The School of Public Policy.

All rights reserved. No part of this publication may be reproduced in any manner whatsoever without written permission except in the case of brief passages quoted in critical articles and reviews.

\section{ISSN}

1919-112x SPP Research Papers (Print)

1919-1138 SPP Research Papers (Online)

\section{DATE OF ISSUE}

September 2011

\section{MEDIA INQUIRIES AND INFORMATION}

For media inquiries, please contact Morten Paulsen at 403-453-0062.

Our web site, www.policyschool.ca, contains more information about The School's events, publications, and staff.

\section{DEVELOPMENT}

For information about contributing to The School of Public Policy, please contact Candice Naylen by telephone at 403-210-7099 or by e-mail at cnaylen@ucalgary.ca.

\section{EDITOR}

Timothy Giannuzzi 


\section{RECENT PUBLICATIONS BY THE SCHOOL OF PUBLIC POLICY}

INVESTMENT REVIEW IN CANADA - WE CAN DO BETTER

http:// policyschool.ucalgary.ca/files/publicpolicy/Herman\%20Invest\%20Canada\%20online.pdf Lawrence L. Herman | September 2011

ENVIRONMENTAL BENEFITS OF USING WIND GENERATION TO POWER PLUG-IN HYBRID ELECTRIC VEHICLES http:/ / policyschool.ucalgary.ca/files/ publicpolicy/enviro\%20hybrid\%20wind\%20energy.pdf

Mahdi Hajian, Monishaa Manickavasagam, William D. Rosehart and Hamidreza Zareipour | August 2011

A FRESH START ON IMPROVING ECONOMIC COMPETITIVENESS AND PERIMETER SECURITY

http:// policyschool.ucalgary.ca/files/ publicpolicy/dburney.pdf

Derek H. Burney | August 2011

PIIGS “Я” US?

http:// policyschool.ucalgary.ca/files/publicpolicy/US\%20debt\%20crisis.pdf

Stephen R. Richardson | July 2011

RHETORIC AND REALITIES: WHAT INDEPENDENCE OF THE BAR REQUIRES OF LAWYER REGULATION http:// policyschool.ucalgary.ca/files/publicpolicy/A_Woolley_lawregulat_c.pdf

Alice Woolley | June 2011

TAX IMPACT OF BC'S HST DEBATE ON INVESTMENT AND COMPETITIVENESS

http:/ / policyschool.ucalgary.ca/files/public policy/tax\%20impact\%20BCHST\%20communique\%20c.pdf Jack Mintz | May 2011

SMALL BUSINESS TAXATION: REVAMPING INCENTIVES TO ENCOURAGE GROWTH

http:// policyschool.ucalgary.ca/files/public policy/mintzchen\%20small\%20business\%20tax\%20c.pdf Duanjie Chen \& Jack Mintz | May 2011

IS THIS THE END OF THE TORY DYNASTY? THE WILDROSE ALLIANCE IN ALBERTA POLITICS http:// policyschool.ucalgary.ca/files/publicpolicy/wildrose\%20online\%20final3.pdf Anthony M. Sayers \& David K. Stewart | May 2011

CANADA'S WORLD CAN GET A LOT BIGGER: THE GROUP OF 20, GLOBAL GOVERNANCE AND SECURITY http:/ / policyschool.ucalgary.ca/files/ publicpolicy/G20\%20Heinbecker.pdf

Paul Heinbecker | May 2011

CAN THE G-20 SAVE THE ENVIRONMENT? POTENTIAL IMPACT OF THE G-20 ON INTERNATIONAL ENVIRONMENT POLICY

http:/ / policyschool.ucalgary.ca/files/publicpolicy/G20\%20.pdf

Barry Carin | April 2011

THE IMPACT OF SALES TAX REFORM ON ONTARIO CONSUMERS:

A FIRST LOOK AT THE EVIDENCE

http:// policyschool.ucalgary.ca/ files/publicpolicy/ontario\%20sales\%20tax\%20reform4.pdf Michael Smart | March 2011

CANADA'S TAX COMPETITIVENESS RANKING: MOVING TO THE AVERAGE BUT BIASED AGAINST SERVICES http:// policyschool.ucalgary.ca/files/ publicpolicy/2010tax\%20comp\%20rank\%20online.pdf Jack Mintz \& Duanjie Chen | February 2011

FEDERAL-PROVINCIAL BUSINESS TAX REFORMS: A GROWTH AGENDA WITH COMPETITIVE RATES AND A NEUTRAL TREATMENT OF BUSINESS ACTIVITIES

http:/ / policyschool.ucalgary.ca/files/ publicpolicy/fed\%20prov\%20tax\%20reform\%201a.pdf Jack Mintz \& Duanjie Chen | January 2011 